Article

\title{
Short-Term Deformability of Three-Dimensional Printable EVA-Modified Cementitious Mortars
}

\author{
Jaeheum Yeon 1 \\ Department of Engineering and Technology, Texas A\&M University-Commerce, Commerce, TX 75429, USA; \\ jaeheum.yeon@tamuc.edu; Tel.: +1-903-468-8115
}

Received: 24 September 2019; Accepted: 30 September 2019; Published: 8 October 2019

\begin{abstract}
This study experimentally examined the deformability of cementitious mortars modified with ethylene-vinyl acetate (EVA) for use in extrusion-based additive construction. The research was based on the author's previous study of the properties of fresh EVA-modified cementitious mixtures for use in additive construction via extrusion. The particular focus was on these mortars' short-term deformation factors, including the modulus of elasticity, drying shrinkage, and thermal expansion. The experimental results indicate that as the EVA/cement ratio was increased, the compressive strength and elastic modulus tended to decrease but the maximum compressive strain increased. At 28 days, the drying shrinkage tended to increase as the EVA/cement ratio was increased. The coefficient of thermal expansion was also found to increase as the EVA/cement ratio was increased. A very high correlation was found between these three deformation factors and the EVA/cement ratio. Given these results, it was determined that the addition of EVA powder to EVA-modified cementitious mortars used in extrusion-based additive construction could adversely affect their short-term deformation factors. However, increasing the EVA/cement ratio resulted in a decrease in the modulus of elasticity, thereby reducing the level of stress caused by drying shrinkage and thermal expansion. This effect will eventually lead to improvements in the degree of extensibility, thereby offsetting the negative impacts. However, it is still desirable to minimize the EVA/cement ratio to the extent that adequate properties for the fresh material can be obtained.
\end{abstract}

Keywords: EVA-modified cementitious mortars; additive construction; short-term deformability; modulus of elasticity; drying shrinkage; coefficient of thermal expansion

\section{Introduction}

Construction processes are intrinsically labor-intensive and accompanied by a high risk of accidents, and thus would benefit from the introduction of automated solutions. The construction industry, however, lags behind other fields in implementing such automation. Encouragingly, an additive construction method intended for concrete structures has recently been developed and applied to small building projects, such as pedestrian bridges [1-3]. Cementitious concrete is one of the most widely used construction materials worldwide, and is mostly in the form of ready-mixed concrete. Cementitious concrete placement, however, typically requires a formwork. Formwork installation costs a great deal in terms of material, human labor, and equipment resources. Also, the construction process is inevitably long term, due to the labor intensity of formwork installation and removal. In addition, the waste produced by formworks may have a negative impact on the environment [4].

The additive construction method was introduced to address these chronic issues associated with concrete work. This process is a computer-controlled construction technology that is used to build structures by layering extruded cementitious concrete without a formwork [5]. Also known as $3 \mathrm{D}$ concrete printing (3DCP), this process was first successfully applied in the construction industry by Khoshnevis [6], who developed a contour crafting (CC) method in which a fresh mixture is first 
extruded in a layer, and then additional layers are added on top. This free-form construction process is possible because the method does not require formwork to construct the cement concrete structure [7].

Compared to conventional construction technologies, $3 \mathrm{DCP}$ is commonly viewed as a sustainable design solution that offers almost unlimited possibilities for implementing geometrically complex designs. The technology is advantageous in various ways, such as in reducing construction cost and time, minimizing environmental degradation. The technology can also be used to streamline environmentally friendly construction processes, reduce industrial waste, and decrease energy consumption resulting from producing the raw materials used in formwork [8].

The 3DCP process consists of three components: a concrete printer, 3D modeling software, and printing material. The procedure draws from three specialized areas, including the mechanical, 3D design, and concrete materials fields [9]. Printing materials comprise the primary concern of the present study, especially cementitious mixtures. In recent relevant research, the most frequently examined materials for 3DCP contained Portland cement, sand, fly ash, and silica fume as base materials, along with small amounts of additives such as superplasticizers and viscosity-modifying agents [4,10-13]. Comparatively speaking, the information available on specific additive construction methods using redispersible ethylene-vinyl acetate (EVA) powder is very limited, even though EVA provides excellent adhesive strength and dynamic cracking resistance [14].

In a previous study conducted by the author, EVA-modified cementitious mortars were produced with various EVA/cement ratios. Then, the properties of fresh EVA-modified cementitious mixtures intended for use in additive construction via extrusion were experimentally investigated [15]. It was clear from this earlier work that EVA-modified cementitious mortars are applicable to the 3DCP process. However, it is still unknown whether or not three-dimensional printable EVA-modified cementitious mortars would be sufficiently stable after the 3DCP process. Thus, in the present study, three-dimensional printable EVA-modified cementitious mortars were experimentally investigated with regard to various properties associated with dimensional stability, such as elasticity and drying and thermal shrinkage. This work provides fundamental research data that will assist in the adoption of EVA-modified cementitious mortars for additive construction applications.

\section{Summary of the Author's Previous Research}

The author, together with collaborators, studied the properties of fresh EVA-modified cementitious mortars as possible materials for use in additive construction [15]. EVA is easier to handle than polymer in a liquid form (i.e., latex or emulsion types), especially when producing mixtures onsite. This is because EVA comes in a powder form. Also, a premixed package that is ready to use onsite can be produced in the factory. Hence, EVA was selected as the object of this series of studies. The main results obtained are as follows.

Determining the optimal flow of EVA-modified cementitious mixtures is of the utmost importance for determining the optimum mix ratio. In the previous study, the author employed a trial-and-error procedure to investigate the ideal flow that would meet all buildability requirements. The flow of each EVA-modified cementitious mixture was tested at 5\% intervals ranging from $50 \%$ to $75 \%$, in order to determine the optimum state. Through this trial-and-error process, the optimal flow was determined to be $65 \%$, as shown in Figures 1 and 2. This flow is considerably lower than the $110 \% \pm 5 \%$ level, which is the standard flow range applied when producing specimens for compressive strength testing under American Society for Testing and Materials (ASTM) C109/C109M-02: Testing Method for Compressive Strength of Hydraulic Cement Mortar [16]. 


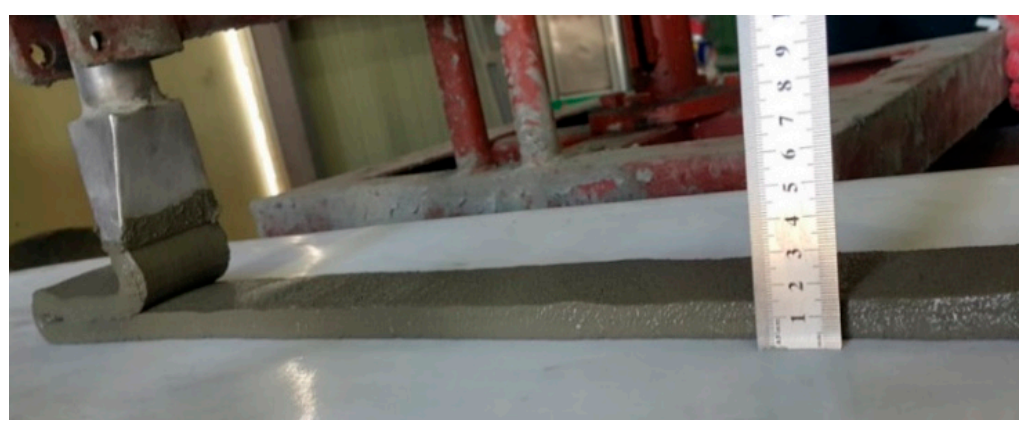

Figure 1. View of the 3D concrete printing (3DCP) process for buildability testing [15].

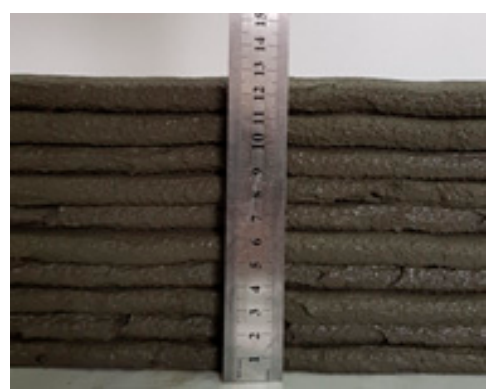

(a) Flow 60\%

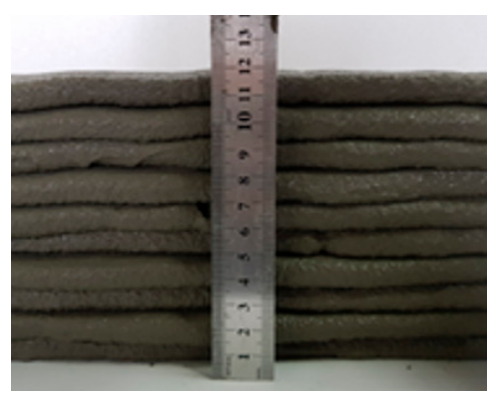

(c) Flow 70\%

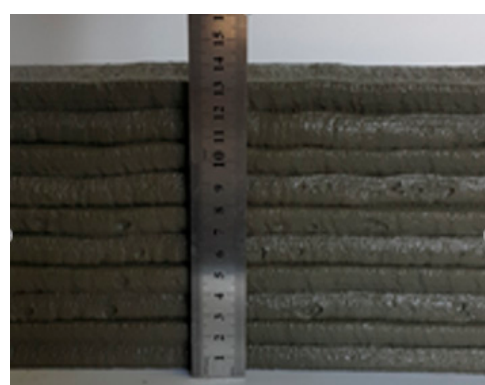

(b) Flow 65\%

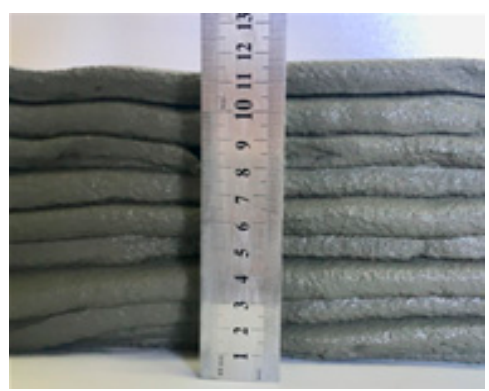

(d) Flow $75 \%$

Figure 2. Test results determining the optimal flow [15].

\subsection{Flowability and Open Time}

Vebe time, compacting factor, slump, and flow test methods are all flowability test methods. Among these, the flow test method is preferable if the workability of the mixture to be tested is to be very high [17]. The results of the flow test conducted for this study showed that the flow increased when the EVA/cement ratio was increased, as shown in Figure 3. This means that the level of the flow loss decreased when the EVA/cement ratio was increased. This result was quite favorable because it indicated that flowability could be secured. Also, the test results showed that the flow consistency improved due to a dispersing effect of the surfactants in the polymers. This effect originated from the ball-bearing action of the polymer particles and entrained air when the EVA powder (which was re-dispersible) was dispersed in the water as the mixture was produced [18].

Open time is the minimum amount of time that a material can be used without a loss of performance. In 3DCP, open time starts at the beginning of extrusion and ends at the time at which there is no more extrusion due to decreased flowability. Hence, open time is the best way to show changes in a mixture's workability over time. Open time can be determined by plotting horizontal lines, as shown in Figure 3. In Figure 3, (1) is the reference point at a $65 \%$ flow, and (2) is the reference point at a $50 \%$ flow, indicating that the mixture can no longer be extruded through the 3DCP process. According to the 
test results, a longer open time was secured when the EVA/cement ratio was increased. These results demonstrate that the time identified was sufficient to complete the 3DCP process. This extended open time originated from a delay in the initial setting. In other words, the initial hydration reaction of the cement was inhibited by the formation of a polymer film [19].

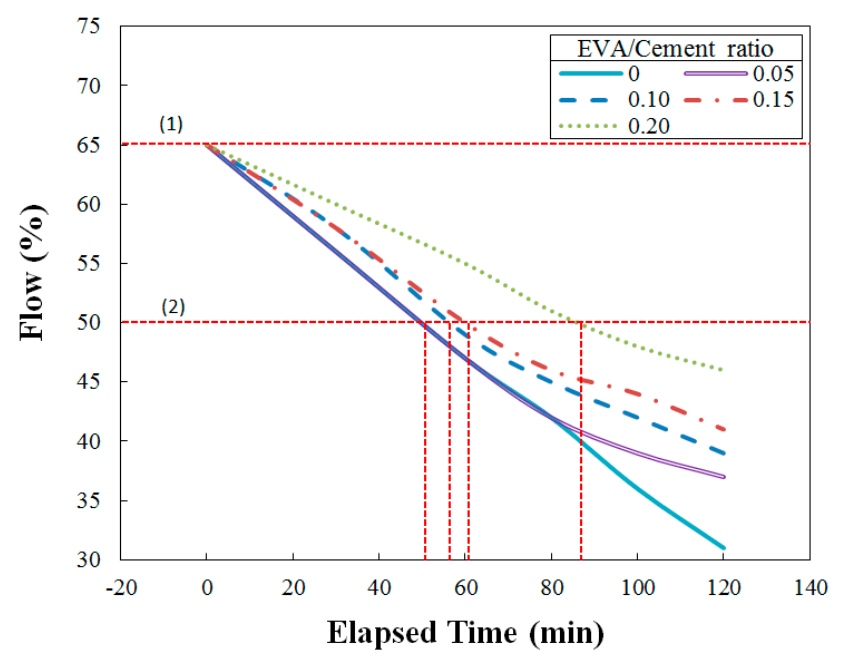

Figure 3. Elapsed time versus flow [15].

\subsection{Buildability}

Buildability was evaluated by measuring the stacked height and its vertical deformation over time after stacking 10 layers with a unit length of $50 \mathrm{~cm}$ per layer. According to the buildability test results, the EVA-modified cementitious mortars proposed in this study showed excellent buildability because the stacked heights experienced a minimal decrease, even though changes were made to the EVA/cement ratio. Among the EVA/ratios tested in this study, the buildability was the most stable when the EVA/ratio was 0.15 ; no vertical deformation was observed. Figure 4 shows the results of the buildability test when the flow of the EVA-modified cementitious mortar samples was $65 \%$. Based on the observations made, no cracks occurred on the surface of the stacked layers at the point where the direction of the nozzle head was changed. However, there were cracks when the EVA/cement ratio was 0 (i.e., plain mortar). The best buildability was observed when the EVA/cement ratio was 0.15-not only were there no cracks, but also the surface at the point where the direction of the nozzle head was changed was smooth. According to the data collected, the occurrence of cohesion due to the viscosity provided excellent resistance to both bleeding and segregation, even though the polymer-modified cementitious mortars had more substantial flowability characteristics as compared to ordinary cementitious mortars [18]. Similar results were observed in a buildability test completed in the earlier study.

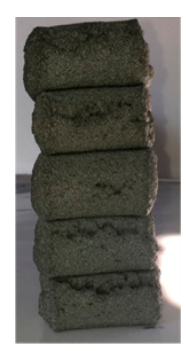

(a) $\mathrm{E} / \mathrm{C}: 0$

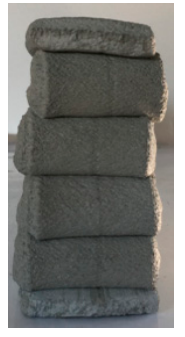

(b) E/C: 0.05

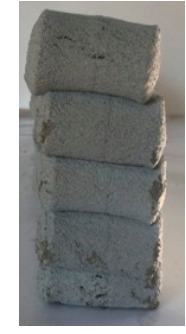

(c) E/C: 0.10

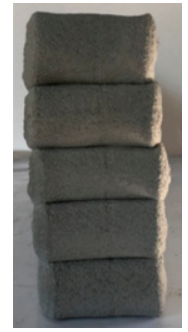

(d) E/C: 0.15

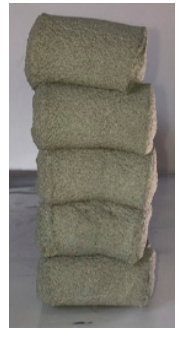

(e) E/C: 0.20

Figure 4. Results of the buildability test at a $65 \%$ flow and different ethylene-vinyl acetate (EVA)/cement ratios [15]. 
In prior research by the author, the properties of fresh EVA-modified cementitious mortars were experimentally investigated with regard to whether those mixtures might be applicable to the 3DCP process. According to the results, it was experimentally determined that EVA-modified cementitious mortars could be employed as 3DCP material. However, the dimensional stability of the EVA-modified cementitious mortars tested could not be estimated because at the time, there had been no study examining the material's deformation properties. Thus, the present research experimentally investigated their dimensional stability.

\section{Materials and Methods}

\subsection{Materials}

The materials used were the same as those employed in the previous study. Ordinary Portland cement, silica sand, fly ash, silica fume, superplasticizer, and viscosity modifying agent were used. Ordinary Portland cement was used as the main binder, fly ash was employed to improve flowability and to inhibit the heat of hydration in the early hydration stage. Also, silica fume was employed to improve the strength.

The characteristics of the materials used in this study are shown in Tables 1-6. The EVA used as a modifier was a white powder. Its product data and chemical constitution are presented in Table 7 and Figure 5, respectively.

Table 1. Properties of ordinary Portland cement (Type I).

\begin{tabular}{ccccccccc}
\hline \multirow{2}{*}{$\begin{array}{c}\text { Density } \\
\left(\mathrm{g} / \mathrm{cm}^{3}\right)\end{array}$} & $\begin{array}{c}\text { Specific Surface } \\
\left(\mathbf{c m}^{2} / \mathbf{g}\right)\end{array}$ & $\mathrm{CaO}$ & $\mathrm{SiO}_{2}$ & $\mathrm{Al}_{2} \mathrm{O}_{3}$ & $\mathrm{Fe}_{2} \mathrm{O}_{3}$ & $\mathrm{SO}_{3}$ & $\mathbf{M g O}$ & Ig. loss \\
\cline { 3 - 8 } & 3630 & 64.10 & 17.00 & 4.44 & 3.88 & 2.97 & 2.34 & 2.76 \\
\hline 3.14 & 3630 & &
\end{tabular}

Table 2. Properties of silica sand.

\begin{tabular}{cccc}
\hline Size(mm) & Apparent Density & Purity (\%) & Water Content (\%) \\
\hline 0.08 & 1.57 & 97.3 & $\leq 0.1$ \\
\hline
\end{tabular}

Table 3. Properties of fly ash.

\begin{tabular}{ccccccccc}
\hline \multirow{2}{*}{$\begin{array}{c}\text { Density } \\
\left(\mathbf{g} / \mathbf{c m}^{3}\right)\end{array}$} & $\begin{array}{c}\text { Specific Surface } \\
\left(\mathbf{c m}^{2} / \mathbf{g}\right)\end{array}$ & $\mathrm{SiO}_{\mathbf{2}}$ & $\mathbf{A l}_{\mathbf{2}} \mathbf{O}_{\mathbf{3}}$ & $\mathbf{C a O}$ & $\mathrm{Fe}_{2} \mathbf{O}_{\mathbf{3}}$ & $\mathrm{SO}_{\mathbf{3}}$ & $\mathbf{M g O}$ & Ig. loss \\
\hline 2.22 & 3651 & 51.90 & 21.80 & 8.25 & 6.93 & 1.02 & 0.89 & 3.20 \\
\hline
\end{tabular}

Table 4. Properties of silica fume.

\begin{tabular}{ccccccccc}
\hline Bulk & Specific & \multicolumn{6}{c}{ Chemical Composition (\%) } \\
\cline { 3 - 9 } $\begin{array}{c}\text { Density-Densified } \\
\left(\mathbf{k g} / \mathbf{m}^{\mathbf{3}}\right)\end{array}$ & $\begin{array}{c}\text { Surface } \\
\left(\mathbf{c m}^{2} / \mathbf{g}\right)\end{array}$ & $\mathbf{S i O}_{\mathbf{2}}$ & $\mathrm{Al}_{\mathbf{2}} \mathbf{O}_{\mathbf{3}}$ & $\mathbf{C a O}$ & $\mathbf{M g O}$ & $\mathbf{F e}_{\mathbf{2}} \mathbf{O}_{\mathbf{3}}$ & $\mathbf{S O}_{\mathbf{3}}$ & Ig. loss \\
\hline $600-700$ & 157,700 & 96.70 & 0.29 & 0.25 & 0.15 & 0.10 & - & 2.39 \\
\hline
\end{tabular}

Table 5. Properties of superplasticizer.

\begin{tabular}{cccc}
\hline Specific Gravity $\left(20^{\circ} \mathrm{C}\right)$ & $\mathbf{p H}$ & Alkali (\%) & Chloride (\%) \\
\hline $1.05 \pm 0.05$ & $5.0 \pm 2.0$ & $\leq 0.01$ & $\leq 0.01$ \\
\hline
\end{tabular}


Table 6. Properties of viscosity modifying agent.

\begin{tabular}{cccc}
\hline Appearance & Bulk Density $\left(\mathbf{k g} / \mathbf{m}^{\mathbf{3}}\right)$ & Moisture Content $\mathbf{( \% )}$ & Particle Size (0.074 $\mathbf{~ m m , ~ \% ) ~}$ \\
\hline White powder & 430 & $\leq 12$ & $\geq 95$ \\
\hline
\end{tabular}

Table 7. Product data for the EVA powder.

\begin{tabular}{cccccc}
\hline $\begin{array}{c}\text { Solids Content } \\
(\%)\end{array}$ & $\begin{array}{c}\text { Ash Content } \\
(\mathbf{\%})\end{array}$ & $\begin{array}{c}\text { Bulk Density } \\
\left(\mathbf{k g} / \mathbf{m}^{\mathbf{3}}\right)\end{array}$ & $\begin{array}{c}\text { Particle Size after } \\
\text { Redispersion } \\
(\mu \mathbf{m})\end{array}$ & $\begin{array}{c}\text { Minimum Film } \\
\text { Forming Temp } \\
\left({ }^{\circ} \mathbf{C}\right)\end{array}$ & $\begin{array}{c}\text { Protective } \\
\text { Colloid }\end{array}$ \\
\hline $98-100$ & $9-13$ & $470-570$ & $0.5-8.0$ & 4 & $\begin{array}{c}\text { Polyvinyl } \\
\text { alcohol (PVA) }\end{array}$ \\
\hline
\end{tabular}<smiles>[Y]C(C)(C)C(CC(C)(C)C([Y])(C)CCC(C)(C)C)OC(C)=O</smiles>

Figure 5. Chemical constitution of EVA.

\subsection{Method}

\subsubsection{Mixture}

As mentioned above, this study was based on the author's previous research, entitled Fresh Properties of EVA-Modified cementitious Mixtures for use in Additive Construction by Extrusion [15]. Hence, the mix proportions applied in the present work were the same as the mix proportions used in the author's prior research. Details related to the mix proportions are summarized in Table 8.

Table 8. Mix proportions of EVA-modified cementitious mortars $\left(\mathrm{kg} / \mathrm{m}^{3}\right)$.

\begin{tabular}{cccccccccc}
\hline $\begin{array}{c}\text { EVA/Cement } \\
\text { Ratio }\end{array}$ & $\begin{array}{c}\text { W/C } \\
\text { Ratio }\end{array}$ & EVA & Cement & Water & $\begin{array}{c}\text { Silica } \\
\text { Sand }\end{array}$ & $\begin{array}{c}\text { Fly } \\
\text { Ash }\end{array}$ & $\begin{array}{c}\text { Silica } \\
\text { Fume }\end{array}$ & $\begin{array}{c}\text { Super- } \\
\text { Plasticizer }\end{array}$ & $\begin{array}{c}\text { Viscosity } \\
\text { Modifying } \\
\text { Agent }\end{array}$ \\
\hline 0 & 0.45 & 0 & 642 & 289 & 1377 & 184 & 92 & 6 & 0.3 \\
0.05 & 0.46 & 32 & 638 & 294 & 1368 & 182 & 91 & 6 & 0.3 \\
0.10 & 0.51 & 63 & 635 & 324 & 1360 & 181 & 91 & 6 & 0.3 \\
0.15 & 0.52 & 95 & 631 & 328 & 1351 & 180 & 90 & 6 & 0.3 \\
0.20 & 0.55 & 125 & 627 & 345 & 1343 & 179 & 90 & 6 & 0.3 \\
\hline
\end{tabular}

\subsubsection{Preparation of Specimens}

Three test specimens were produced for each EVA/cement ratio (i.e., test variable). Among each set of three test results produced for each EVA/cement ratio, the middle value was selected because all of the results appeared continuously. Casting the specimens with mortar directly extruded into the formwork created many voids, resulting in significant data errors. Hence, ASTM C109/C109M-02: Standard Test Method for Compressive Strength of Hydraulic Cement Mortars [16] was applied to produce the specimens. These specimens were cured at a temperature of $23 \pm 2{ }^{\circ} \mathrm{C}$ and a relative humidity of $65 \% \pm 5 \%$. Also, the cylindrical specimens used for the compressive stress-strain tests were ground for planeness before the tests were conducted. 


\subsubsection{Test of Modulus of Elasticity}

The modulus of elasticity was measured with respect to ASTM C 469M-14: Standard Test Method for Static Modulus of Elasticity and Poisson's Ratio of Concrete in Compression [20]. Cylindrical specimens (50 $\mathrm{mm}$ in diameter, $100 \mathrm{~mm}$ long) were employed in the tests. Loads were applied via the load-controlled method and the rate of application of compressive stress was $0.25 \mathrm{MPa} / \mathrm{s}$. The elastic modulus equation applied in the present study is shown in Equation (1), and the input data were extracted from compressive stress-strain curves. The strain was measured using an electric resistance-type strain gauge and data logger (Tokyo Sokki, TDS-602). A schematic of the system is presented in Figure 6.

$$
E=\frac{S_{2}-S_{1}}{\varepsilon_{2}-0.000050}
$$

where $E$ is the chord modulus of elasticity (MPa), $S_{1}$ is the stress corresponding to a longitudinal strain of $0.00005(\mathrm{MPa}), S_{2}$ is the stress corresponding to $40 \%$ of the ultimate load (MPa), and $\varepsilon_{2}$ is the longitudinal strain produced by stress $S_{2}$.

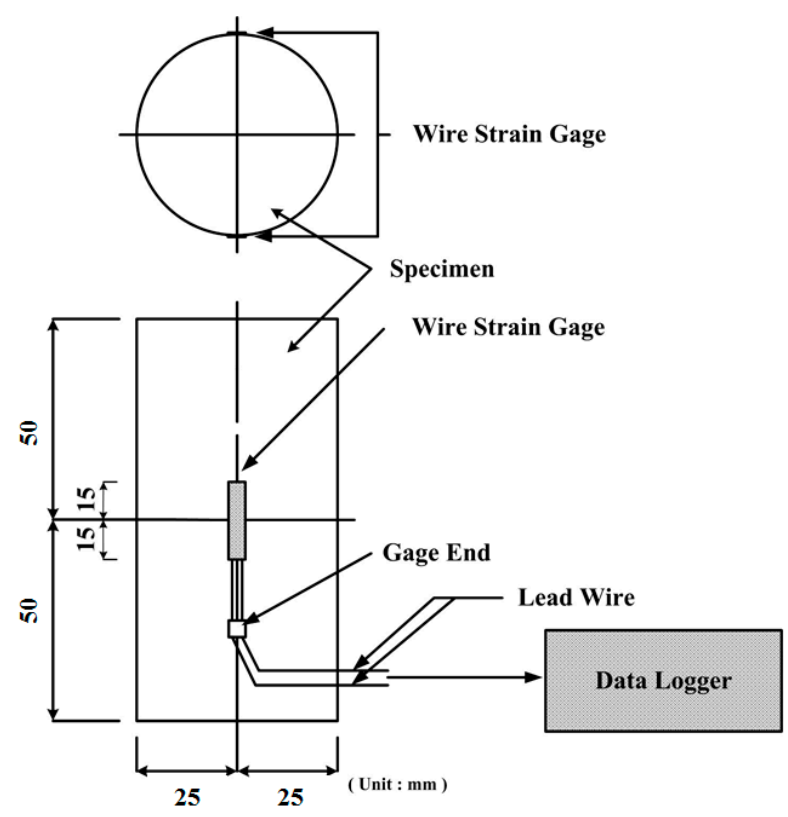

Figure 6. Conceptual drawing of the strain measurement system.

\subsubsection{Test of Drying Shrinkage}

Drying shrinkage tests were carried out with respect to ASTM C596-01: Standard Test Method for Drying Shrinkage of Mortar Containing Hydraulic Cement [21], using an environmental chamber held at a temperature of $23 \pm 2{ }^{\circ} \mathrm{C}$ and relative humidity of $65 \% \pm 5 \%$. The specimen dimensions were $70 \mathrm{~mm} \times 70 \mathrm{~mm} \times 320 \mathrm{~mm}$. The longitudinal strain was measured at the center of the cross-section using an embedded-type strain gauge (Tokyo Sokki, PMFL-series) and data logger (Tokyo Sokki, TDS-602) since placement. After $24 \mathrm{~h}$ curing in the molds with an air-tight plastic sheet placed on the top surface, the specimens were demolded for external drying; the shrinkage up to the first $24 \mathrm{~h}$ was also monitored to measure autogenous shrinkage. The procedure for installing the strain gauge is described in Figure 7. 


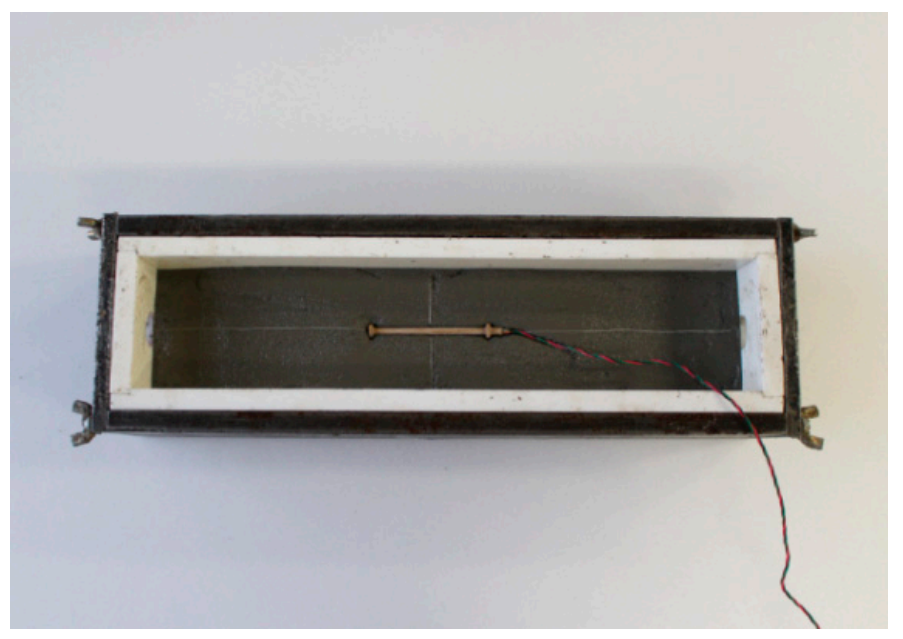

Figure 7. Test setup for measuring drying shrinkage.

\subsubsection{Test of Thermal Expansion}

Thermal expansion tests were carried out with respect to ASTM C531-18: Standard Test Method for Linear Shrinkage and Coefficient of Thermal Expansion of Chemical Resistance Mortars, Grouts, Monolitic Surfacings, and Polymer Concretes [22]. The temperature was increased from $25^{\circ} \mathrm{C}$ to $80^{\circ} \mathrm{C}$ once the thermal equilibrium was achieved throughout the specimen. The specimen dimensions and procedure for instrumentation were the same as in the drying shrinkage tests, shown in Figure 7. To determine the true thermal strain, thermal calibration was performed.

\section{Results and Discussion}

\subsection{Stress-Strain Relationship and Modulus of Elasticity}

Stress-strain curves provide basic data for estimating the modulus of elasticity. Given that concrete is not completely elastic, however, estimating the elastic modulus based on these curves results in various issues. Strictly speaking, the modulus of elasticity only applies to the linear elastic section of the stress-strain curve. In cases where it is difficult to judge the linear elastic section from the curved part, as is the case with concrete, the secant modulus of elasticity, also known as the chord modulus, is alternatively used [23]. In extrusion-based additive construction, the modulus of elasticity is a critical factor that is used to estimate both the stress caused by drying shrinkage in layered EVA-modified cementitious mortar $\left(\sigma=\varepsilon_{s h} E\right)$ and the stress caused by thermal expansion $(\sigma=\alpha E \Delta T)$.

In concrete, stress and strain typically have a non-linear relationship, but the relationship can be considered the linear elastic section at a lower stress level. This stress range can reach up to $40 \%$ of the ultimate strength, within which concrete can be considered an elastic material.

The stress-strain diagrams of the developed EVA-modified cementitious mortars are presented in Figure 8. The shapes of these curves resemble those obtained for cementitious paste [23]. Based on these diagrams, the obtained compressive strengths were $48.3 \mathrm{MPa}, 41.8 \mathrm{MPa}, 38.2 \mathrm{MPa}$, 35.7 MPa, and 33.5 MPa when the EVA/cement ratios were $0,0.05,0.10,0.15$, and 0.20 , respectively. The compressive strength decreased as the EVA/cement ratio increased. The secant modulus was calculated using Equation (1). The results were $21.6 \mathrm{GPa}, 19.1 \mathrm{GPa}, 18.1 \mathrm{GPa}, 17.6 \mathrm{GPa}$, and $16.7 \mathrm{GPa}$ when the $\mathrm{EVA} /$ cement ratios were $0,0.05,0.10,0.15$, and 0.20 , respectively. The relationship between these elastic modulus measurements and the applied EVA/cement ratios was analyzed, as presented in Figure 9. A high correlation was found (i.e., the modulus of elasticity tended to decrease as the EVA/cement ratio was increased). 


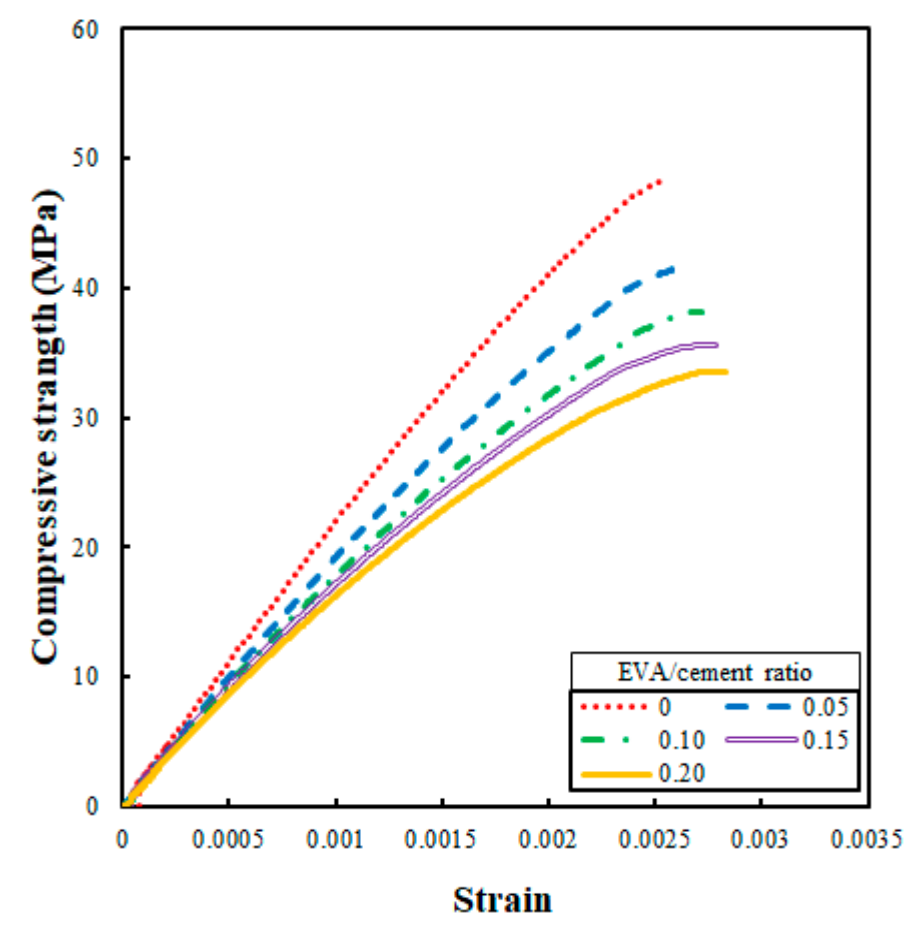

Figure 8. Stress-strain diagrams for different EVA/cement ratios.

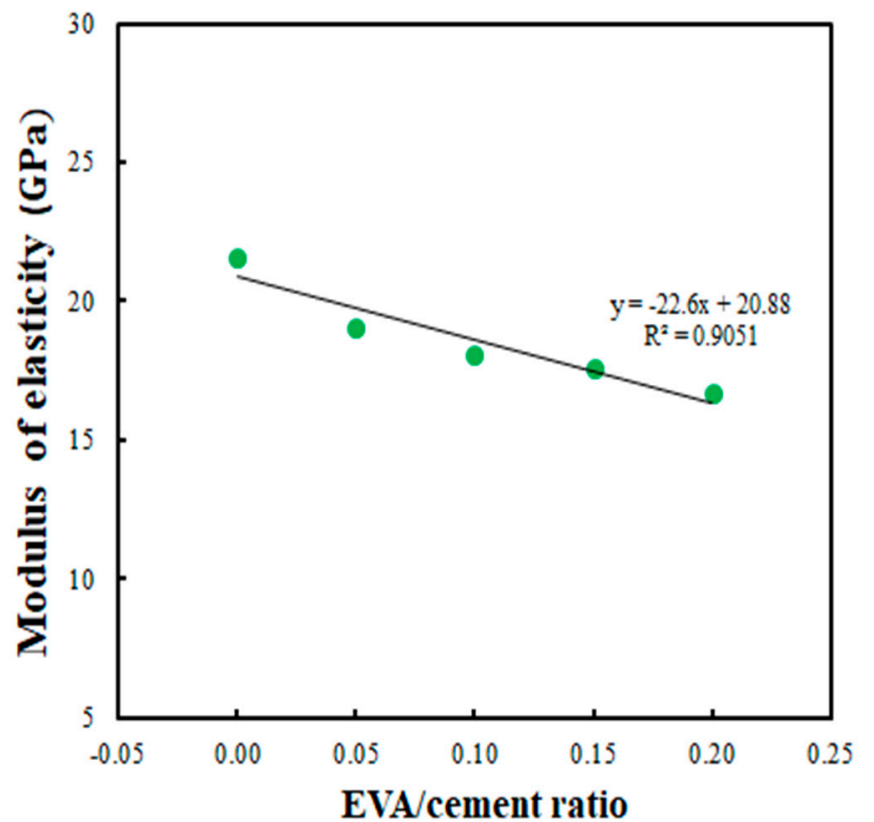

Figure 9. Relationship between the EVA/cement ratio and modulus of elasticity.

Earlier studies showed that the modulus of elasticity in the compression of unmodified cementitious concrete was $21.1 \mathrm{GPa}$, while the value ranges were $22.4 \mathrm{GPa}$ to $23.6 \mathrm{GPa}, 20.2 \mathrm{GPa}$ to $24.3 \mathrm{GPa}$, and 10.0 GPa to 19.0 GPa for polyacrylic ester (PAE)-modified cementitious concrete, styrene butadiene rubber (SBR)-modified cementitious concrete, and polyvinyl acetate (PVAC)-modified cementitious concrete, respectively [18]. The results varied depending on the polymer type and polymer/cement ratio. Overall, the modulus of elasticity tended to decrease as the polymer/cement ratio increased, and the degree of reduction increased when the polymer content was excessive. A decrease in the elastic modulus reduces the stiffness of EVA-modified cementitious mortar but also decreases the level of stress caused by drying shrinkage and temperature change. 
It is also known that the modulus of elasticity of polymer-modified cementitious mortar is relatively low, $10 \mathrm{GPa}$ to $30 \mathrm{GPa}$, because it contains polymer (elastic modulus: $0.1 \mathrm{GPa}$ to $10 \mathrm{GPa}$ ) [24]; the elastic modulus of cementitious concrete in compression generally falls within the range of $14 \mathrm{GPa}$ to $40 \mathrm{GPa}$ [17]. In the present research, the maximum compressive strains were $0.00256,0.00267$, $0.00272,0.00278$, and 0.00283 when the EVA/cement ratios were $0,0.05,0.10,0.15$, and 0.20 , respectively. These results indicate that the maximum compressive strain tended to increase as the EVA/cement ratio increased. Given that the figures were 0.002 and 0.0027 for $30 \mathrm{MPa}$ cement concrete and $34 \mathrm{MPa}$ cement paste [23], respectively, the measured maximum compressive strains were found to be comparable to that of cement paste. Concrete in compression shows some inelastic strain before failure. It is worth noting that the typical level of strain at failure is 0.002 [17] and the strain of $100 \mathrm{MPa}$ concrete is typically 0.003 to 0.004 , while the strain of $20 \mathrm{MPa}$ concrete is 0.002 . Each stress corresponds to the ultimate strength. However, under the same stress, regardless of strength, stronger concrete exhibits a lower strain [23].

In addition, the relationship between the compressive strength and estimated modulus of elasticity was analyzed, as presented in Figure 10. Here, the modulus of elasticity tended to increase with increases in compressive strength. It is highly certain that in concrete, the compressive strength and modulus of elasticity have a proportional relationship, but an agreement has not been reached on the precise form of that relationship [23]. As a result, thus far the American Concrete Institute (ACI) Building Code and the Comit Euro-International du B ton and the $\mathrm{F} \mathrm{d}$ ration International de la Pr contrainte (CEB-FIP) Model Code have proposed different equations [17]. In the present study, the relationship between the modulus of elasticity and compressive strength of each EVA-modified cementitious mortar was derived as shown in Equation (2):

$$
E_{c}=1.41\left(f_{c}^{\prime}\right)^{0.7}
$$

where $E_{c}$ is the modulus of elasticity (GPa) and $f^{\prime}{ }_{c}$ is the compressive strength in MPa.

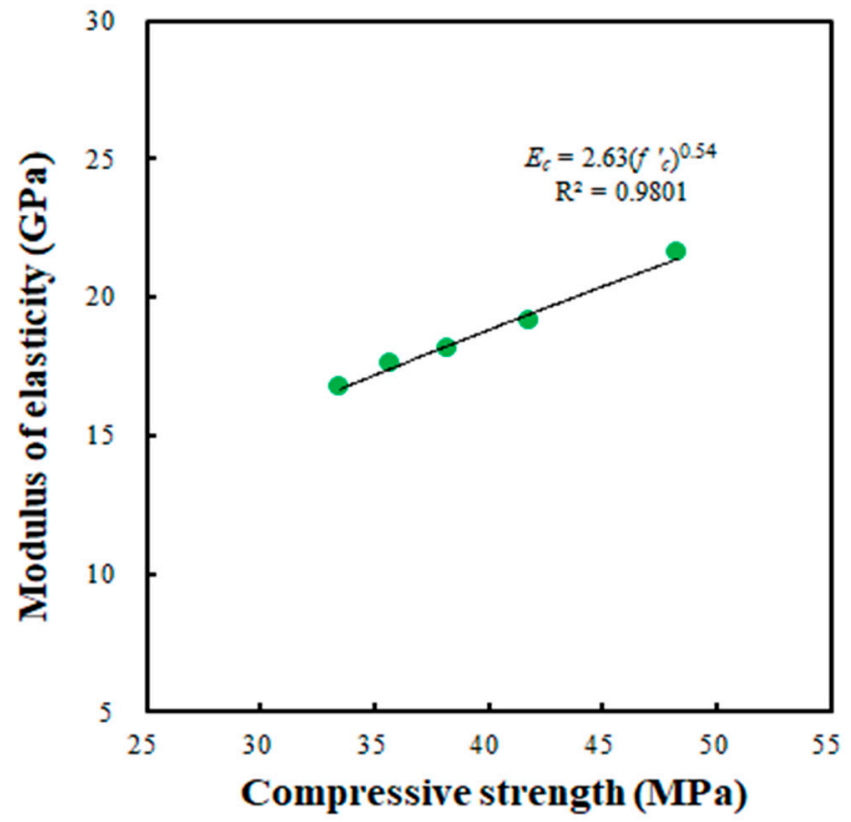

Figure 10. Relationship between the compressive strength and modulus of elasticity.

\subsection{Drying Shrinkage}

Drying shrinkage is one of the major causes of cracking in concrete. Once exposed to air, concrete starts to dry out and the dried surface contracts. The internal moisture, however, suppresses shrinkage 
in the outer part. Accordingly, the surface regions undergo tensile stresses, and when the stress-induced drying shrinkage exceeds the direct tensile strength of the concrete, cracking occurs.

One advantage of 3DCP is that formwork is not necessary. This removes a barrier between the curing concrete and ambient environment. Printed layers often have a greater exposed surface area than cast concrete. However, lower water/cement ratios than those seen in casting concrete are typical in 3DCP mortars. Hence, the likelihood of cracking resulting from autogenous shrinkage is increased. Therefore, mix designs must minimize dimensional changes due to dry and autogenous shrinkage and greater care should be taken when curing [25].

In typical cementitious mortar and concrete, the degree of drying shrinkage ranges from $200 \times 10^{-6}$ to $1200 \times 10^{-6}$, depending on the aggregate/cement ratio [26]. Figure 11 presents the drying shrinkage test results for up to 28 days in relation to the EVA/cement ratio. Figure 11a shows the results for up to $24 \mathrm{~h}$, while Figure $11 \mathrm{~b}$ indicates the results for up to 28 days. Here, the results are presented in two separate figures to make the initial-stage strain caused by drying shrinkage more distinct.

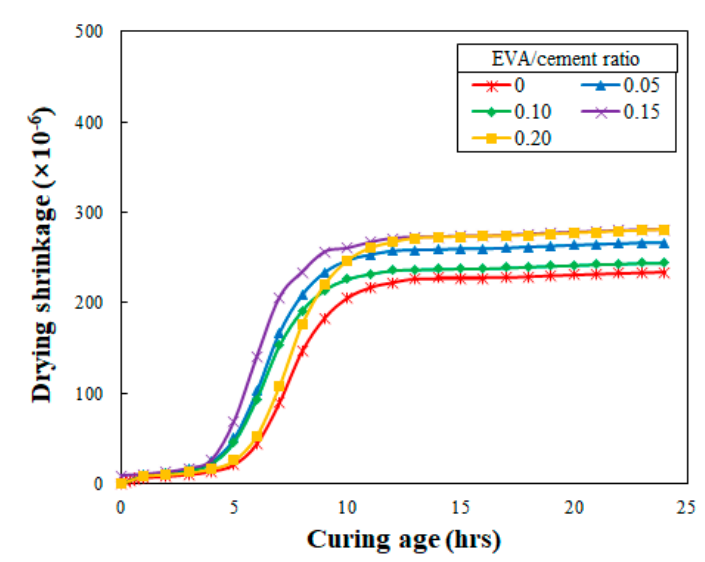

(a)

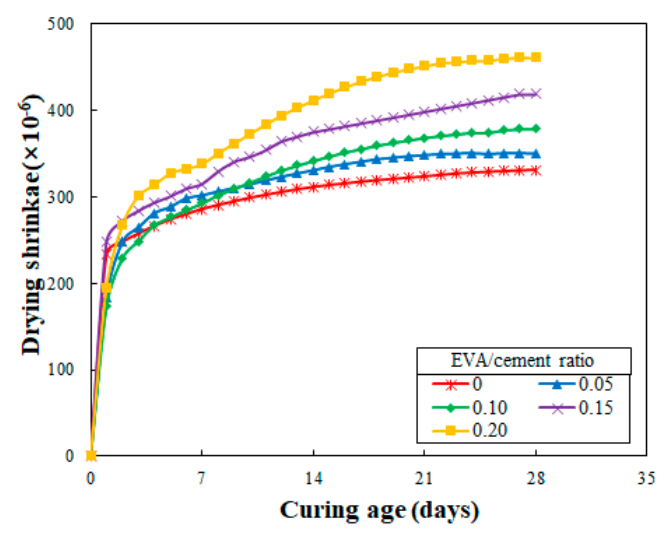

(b)

Figure 11. Drying shrinkages for different EVA/cement ratios at (a) $24 \mathrm{~h}$ and (b) 28 days.

One hour after placement, autogenous shrinkage was initiated; substantial shrinkage occurred from 4 to $11 \mathrm{~h}$. After demolding, drying shrinkage continued to increase until 28 days. At 28 days, the drying shrinkage was $331 \times 10^{-6}, 349 \times 10^{-6}, 379 \times 10^{-6}, 418 \times 10^{-6}$, and $461 \times 10^{-6}$ when the EVA/cement ratios were $0,0.05,0.10,0.15$, and 0.20 , respectively, indicating that the shrinkage increased as the EVA/cement ratio increased (see Figure 12). Based on these results, an increased rate was calculated when the EVA/cement ratio of zero was set as a reference. The rates were $5 \%, 14 \%, 26 \%$, and $39 \%$ when the EVA/cement ratios were $0.05,0.10,0.15$, and 0.20 , respectively. This drying shrinkage development trend was related to an increase in the water/cement ratio from 0.45 to 0.55 with an increase in the EVA/cement ratio, as shown in Table 8. This is considered a disadvantage of the redispersible EVA powder.

In a previous study by Weng et al. [27], at 28 days and a water/cement ratio of 0.5 , the drying shrinkages were $0.0128 \%, 0.0217 \%, 0.0222 \%$, and $0.0224 \%$ when the EVA/cement ratios were $0,0.03$, 0.05 , and 0.08 , respectively. When the water/cement ratio was 0.6 , the drying shrinkages were $0.0380 \%$, $0.0527 \%, 0.0538 \%$, and $0.0546 \%$ and the $\mathrm{EVA} /$ cement ratios were $0,0.03,0.05$, and 0.08 , respectively. This indicates that the drying shrinkage increased as both the EVA/cement ratio and water/cement ratio increased. 


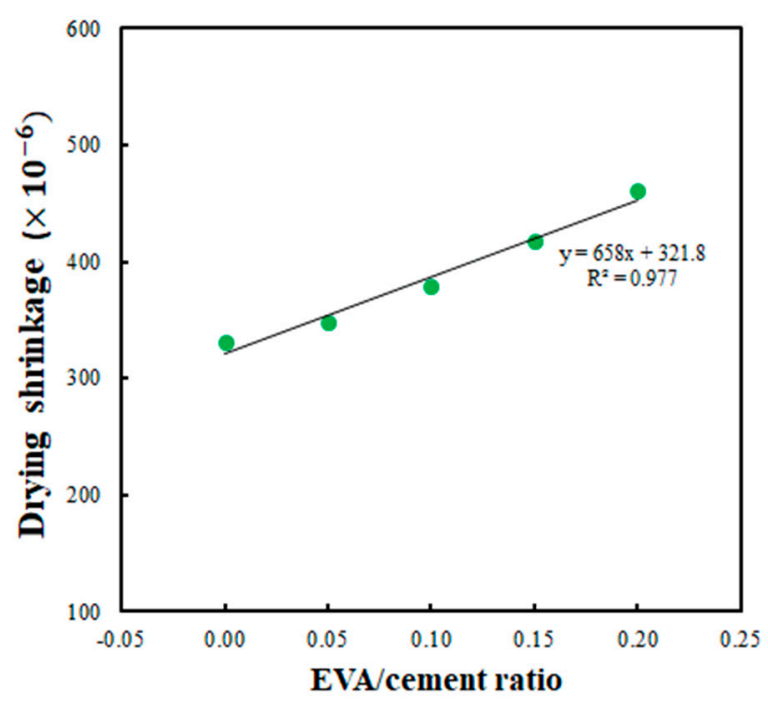

Figure 12. Relationship between EVA/cement ratio and drying shrinkage.

In contrast, in SBR latex-modified cementitious mixtures, drying shrinkage was reported to decrease with an increase in polymer content $[19,24,28]$. Likewise, when modified with latex, cementitious mortar exhibited less drying shrinkage; this is ascribed to the effects of the surfactants and antifoamers contained in the latex [29]. The significant drying shrinkage seen in EVA-modified cementitious mixtures can be significantly reduced by using shrinkage reducing agents such as polyethylene glycol [30] and ethylene [18], but attention must be paid when following this course because adverse effects, such as strength degradation, may occur.

\subsection{Coefficient of Thermal Expansion}

The coefficient of thermal expansion is defined as the change in the unit length of a material for a unit change in temperature. Thermal shrinkage strain is determined by the degree of temperature drop in concrete and its coefficient of linear thermal expansion [17]. The coefficient of the thermal expansion of concrete is determined by the combined values of the dissimilar thermal coefficients of its two main constituents (i.e., cement paste and aggregates) [23]. Concrete structures are deformed by temperature variations resulting from the hydration reaction of cement or atmospheric temperature changes. When this temperature variation causes the tensile stress of concrete to exceed its tensile stress, cracking is initiated. Layered cementitious materials built through extrusion-based additive construction are expected to undergo cracking and delamination due to temperature change.

In the present study, thermal strain tests were conducted, and the results are presented in Figure 13. The thermal strains were $437 \times 10^{-6}, 530 \times 10^{-6}, 643 \times 10^{-6}, 812 \times 10^{-6}$, and $997 \times 10^{-6}$ when the $\mathrm{EVA} /$ cement ratios were $0,0.05,0.10,0.015$, and 0.020 , respectively. It was found that in all cases, the thermal strain was reached within about two hours. The coefficient of thermal expansion was estimated by dividing each thermal strain measurement by the corresponding temperature rise. Once calculated, its relationship with the EVA/cement ratio was analyzed, as shown in Figure 14. Here, the coefficients of thermal expansion were $7.9 \times 10^{-6} /{ }^{\circ} \mathrm{C}, 9.6 \times 10^{-6} /{ }^{\circ} \mathrm{C}, 11.7 \times 10^{-6} /{ }^{\circ} \mathrm{C}, 14.8 \times 10^{-6} /{ }^{\circ} \mathrm{C}$, and $18.1 \times 10^{-6} /{ }^{\circ} \mathrm{C}$ when the EVA/cement ratios were $0,0.05,0.10,0.15$, and 0.20 , respectively. This indicates that the thermal expansion coefficient tended to increase as the EVA/cement ratio increased, and the correlation between the two factors was high.

Previous studies have reported that the coefficient of thermal expansion of polymer-modified cementitious mortar ranged from $9 \times 10^{-6} /{ }^{\circ} \mathrm{C}$ to $10 \times 10^{-6} /{ }^{\circ} \mathrm{C}$ [24]. Notably, however, when the polymer/cement ratio ranged from 0.10 to 0.20 , the coefficient of thermal expansion of SBR latex-modified cementitious mortar was reported to be between $7.7 \times 10^{-6} /{ }^{\circ} \mathrm{C}$ and $8.6 \times 10^{-6} /{ }^{\circ} \mathrm{C}$, which was not significantly different from that of unmodified mortar at $7.9 \times 10^{-6} /{ }^{\circ} \mathrm{C}$ [18]. For ordinary cementitious 
concrete, Neville [23] reported that the coefficient of linear thermal expansion of hydrated cementitious paste varied from $11 \times 10^{-6} /{ }^{\circ} \mathrm{C}$ to $20 \times 10^{-6} /{ }^{\circ} \mathrm{C}$. Mehta et al. [17] presented that the coefficient of linear thermal expansion of cementitious mortars was approximately $18 \times 10^{-6} /{ }^{\circ} \mathrm{C}$ for cementitious paste, $12 \times 10^{-6} /{ }^{\circ} \mathrm{C}$ for mortar, and between $6 \times 10^{-6} /{ }^{\circ} \mathrm{C}$ and $12 \times 10^{-6} /{ }^{\circ} \mathrm{C}$ for concrete. As explained above, the measured coefficient of thermal expansion was determined to be significantly higher in the present study when compared to the results reported by previous studies on polymer-modified cementitious mortars. At the same time, the coefficient of thermal expansion of ordinary cementitious concrete and mortars measured in the present study was largely comparable to those reported in similar previous research.

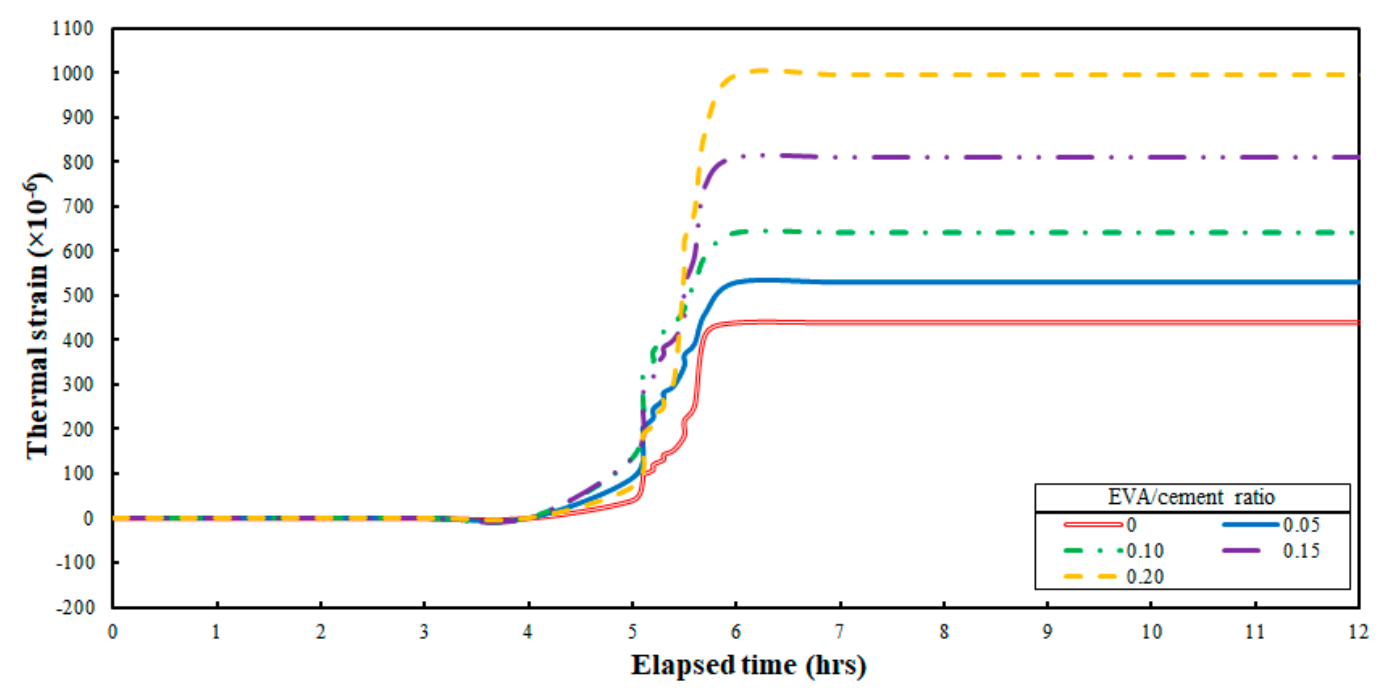

Figure 13. Thermal strains for different EVA/cement ratios.

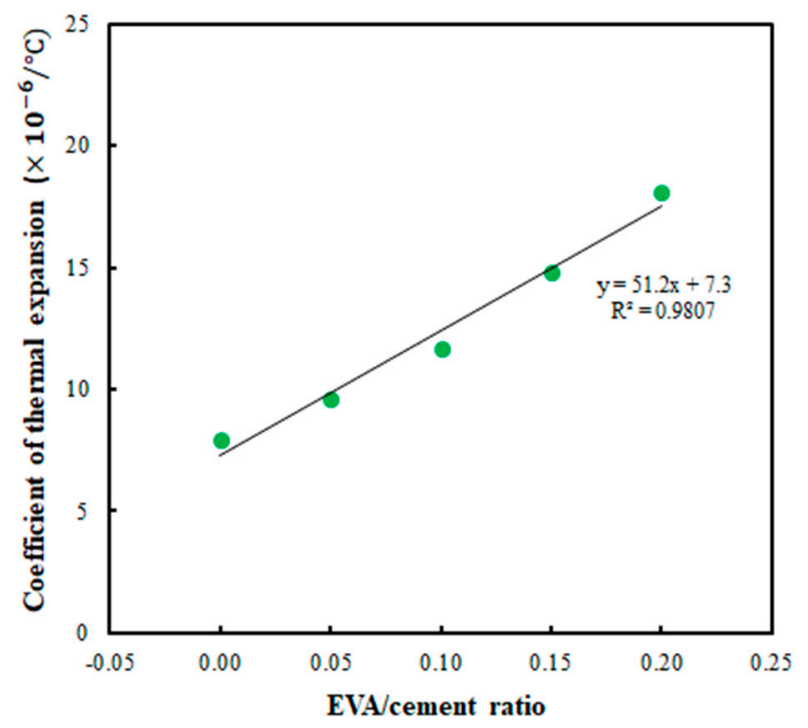

Figure 14. Relationship between the EVA/cement ratio and coefficient of thermal expansion.

\section{Conclusions}

EVA powder is easier to handle onsite than liquid polymer (i.e., latex or emulsion types) with regards to pre-mixing. Hence, EVA was selected as the admixture used to produce the 3D-printable EVA-modified cementitious mortars examined here. This research is a follow-up study to previous research published by the author, entitled Fresh Properties of EVA-Modified Cementitious Mixtures for use in Additive Construction by Extrusion. The present study experimentally examined 
the short-term deformability of EVA-modified cementitious mortar for extrusion-based additive construction, especially with regards to the elastic modulus, drying shrinkage, and thermal expansion. These three factors are critical for determining the properties of hardened materials used in additive construction. The major findings of this study are as follows.

As the EVA/cement ratio was increased, the compressive strength and elastic modulus tended to decrease but the maximum compressive strain increased. Drying shrinkage began one hour after the mortar was placed, was most significant in the $4-11 \mathrm{~h}$ range, and continued to increase until 28 days of aging. At 28 days, the drying shrinkage tended to increase as the EVA/cement ratio was increased. The thermal expansion coefficient also tended to increase as the EVA/cement ratio was increased. A correlation analysis indicated that each of the three factors (i.e., elastic modulus, drying shrinkage, and thermal expansion) had a high determination coefficient $\left(\mathrm{r}^{2}\right)$ with regards to the EVA/cement ratio.

Of the three factors described above, drying shrinkage and thermal expansion increased as the $\mathrm{EVA} / \mathrm{cement}$ ratio was increased, indicating that the materials concerned were disadvantageous in terms of dimensional stability. At the same time, the elastic modulus decreased; thus, the level of stress caused by the other two factors may also have been reduced, thereby improving the degree of extensibility and offsetting any adverse impact. That being said, in order to increase the elastic modulus while reducing the degree of drying shrinkage and thermal expansion, it is still desirable to reduce the water/cement ratio by reducing the $\mathrm{EVA} / \mathrm{cement}$ ratio.

Funding: This research received no external funding.

Acknowledgments: The author is very grateful to former collaborators Kwan-Kyu Kim and Hee Jun Lee from Korea Conformity Laboratories and Kangwon National University for the assistance in conducting the experiment.

Conflicts of Interest: The author declares no conflicts interest.

\section{References}

1. Chinese Company Assembles 10 3D-Printed Concrete Houses in a Day for Less Than $\$ 5,000$ Each. Available online: https://inhabitat.com/chinese-company-assembles-ten-3d-printed-concrete-houses-in-one-day-forless-than-5000-each/ (accessed on 1 September 2019).

2. Apis Cor and Gerdau to Print Homes Together on Earth and Beyond. Available online: https://www.apis-cor. com/apiscor-and-gerdau (accessed on 1 September 2019).

3. TU/e and BAM Infra Get to Work on 3D Printed Concrete Bicycle Bridge. Available online: https: //3dprint.com/178462/eindhoven-3d-printed-bridge/ (accessed on 1 September 2019).

4. Nerella, V.N.; Mechtcherine, V. Studying the printability of fresh concrete for formwork-free concrete onsite 3D printing technology (CONPrint3D). In 3D Concrete Printing Technology, 1st ed.; Sanjayan, J.G., Nazari, A., Nematollahi, B., Eds.; Elsevier: Amsterdam, The Netherlands, 2019; Volume 16, pp. 333-347.

5. Rushing, T.S.; Stynoski, P.B.; Barna, L.A.; Al-Chaar, G.K.; Burroughs, J.F.; Shannon, J.D.; Kreiger, M.A.; Case, M.P. Investigation of concrete mixtures for additive construction. 3D concrete printing technology. In 3D Concrete Printing Technology, 1st ed.; Sanjayan, J.G., Nazari, A., Nematollahi, B., Eds.; Elsevier: Amsterdam, The Netherlands, 2019; Volume 7, pp. 137-160.

6. Khoshnevis, B. Automated Construction by Contour Crafting-Related Robotics and Information Technologies. Autom. Constr. 2004, 13, 5-19. [CrossRef]

7. Tay, Y.W.D.; Panda, B.; Paul, S.C.; Noor Mohamed, N.A.; Tan, M.J.; Leong, K.F. 3D Printing Trends in Building and Construction Industry: A Review. Virtual Phys. Prot. 2017, 12, 261-276. [CrossRef]

8. Hager, I.; Golonka, A.; Putanowicz, R. 3D Printing of Buildings and Building Components as the Future of Sustainable Construction? Proc. Eng. 2016, 151, 292-299. [CrossRef]

9. Yeon, K.S.; Kim, K.K.; Yeon, J. Feasibility study of the use of polymer-modified cement composites as 3D concrete printing material. In Proceedings of the International Congress in Polymers in Concrete, Washington, DC, USA, 29 April-1 May 2018; Taha, M.R., Ed.; Springer: Berlin, Germany, 2018.

10. Bentz, D.P.; Jones, S.Z.; Bentz, I.R.; Peltz, M.A. Towards the formulation of robust and sustainable cementitious binders for 3D additive construction by extrusion. In 3D Concrete Printing Technology, 1st ed.; Sanjayan, J.G., Nazari, A., Nematollahi, B., Eds.; Elsevier: Amsterdam, The Netherlands, 2019; Volume 15, pp. 307-331. 
11. Kazmian, A.; Yuan, X.; Meier, R.; Khoshnevis, B. Performance-based testing portland cement concrete for construction-scale 3D printing. In 3D Concrete Printing Technology, 1st ed.; Sanjayan, J.G., Nazari, A., Nematollahi, B., Eds.; Elsevier: Amsterdam, The Netherlands, 2019; Volume 2, pp. 13-35.

12. Li, Z.; Wang, L.; Ma, G. Method for the enhancement of buildability and bending resistance of three-dimensional-printable tailing mortar. In 3D Concrete Printing Technology, 1st ed.; Sanjayan, J.G., Nazari, A., Nematollahi, B., Eds.; Elsevier: Amsterdam, The Netherlands, 2019; Volume 8, pp. 161-180.

13. Weng, Y.; Li, M.; Tan, M.J.; Qian, S. Design 3D printing cementitious materials via Fuller Thompson Theory and Marson-Percy Model. In 3D Concrete Printing Technology, 1st ed.; Sanjayan, J.G., Nazari, A., Nematollahi, B., Eds.; Elsevier: Amsterdam, The Netherlands, 2019; Volume 14, pp. 281-306.

14. Wu, Y.Y.; Ma, B.G.; Wang, J.; Zhang, F.C.; Jian, S.W. Study on Interface Properties of EVA-Modified Cement Mortar. Adv. Mater. Res. 2011, 250-253, 875-880. [CrossRef]

15. Yeon, K.; Kim, K.K.; Yeon, J.; Lee, H.J. Fresh Properties of EVA-Modified Cementitious Mixtures for Use in Additive Construction via Extrusion. Materials 2019, 12, 2292. [CrossRef] [PubMed]

16. Ohama, Y. Handbook of Polymer-Modified Concrete and Mortars, 1st ed.; Noyes Publications: Park Ridge, NJ, USA, 1995.

17. Mehta, P.K.; Monteiro, P.J.M. Concrete: Microstructure, Properties, and Materials, 3rd ed.; McGraw-Hill: New York, NY, USA, 2006.

18. ASTM C109/C109M-02. Standard Test Method for Compressive Strength of Hydraulic Cement Mortars. Available online: https://www.astm.org/DATABASE.CART/HISTORICAL/C109C109M-02.htm (accessed on 1 September 2019).

19. Ohama, Y.; Kan, S. Effects of Specimen Size on Strength and Drying Shrinkage of Polymer-Modified Concrete. Int. J. Cem. Compos. Lightweight Concr. 1982, 4, 229-233. [CrossRef]

20. ASTM C469/C469M-14. Standard Test Method for Static Modulus of Elasticity and Poisson's Ratio of Concrete in Compression. Available online: https://www.astm.org/Standards/C469 (accessed on 1 September 2019).

21. ASTM C596-01. Standard Test Method for Drying Shrinkage of Mortar Containing Hydraulic Cement. Available online: https://www.astm.org/DATABASE.CART/HISTORICAL/C596-01.htm (accessed on 1 September 2019).

22. ASTM C531-18. Standard Test Method for Linear Shrinkage and Coefficient of Thermal Expansion of Chemical-Resistant Mortars, Grouts, Monolithic Surfacings, and Polymer Concretes. Available online: https://www.astm.org/Standards/C531.htm (accessed on 1 September 2019).

23. Neville, A.M. Properties of Concrete, 4th ed.; John Wiley \& Sons Inc.: Hoboken, NJ, USA, 1996.

24. Chandra, S.; Ohama, Y. Polymers in Concrete, 1st ed.; CRC Press: Boca Raton, FL, USA, 1994.

25. Buswell, R.A.; Leal de Silva, W.R.; Jones, S.Z.; Dirrenberger, J. 3D Printing Using Concrete Extrusion: A Road Map for Research. Cem. Concr. Res. 2018, 112, 37-49. [CrossRef]

26. Lea, F.M. The Chemistry of Cement and Concrete, 3rd ed.; Chemical Publishing Company: New York, NY, USA, 1970.

27. Weng, T.L.; Lin, W.T.; Li, C.H. Properties Evaluation of Repair Mortars Containing EVA and VA/VeoVa Polymer Powders. Polym. Polym. Compos. 2017, 25, 77-86. [CrossRef]

28. Kardon, J.B. Polymer-Modified Concrete: Review. J. Mater. Civ. Eng. 1997, 9, 85-92. [CrossRef]

29. Kawano, T. Studies on the mechanism of reducing drying shrinkage of cement mortar modified by rubber latex. In Proceedings of the Third International Congress on Polymers in Concrete, Koriyama, Japan, 13-15 May 1981; Transport Research Laboratory: Wokingham, UK, 1981.

30. Kim, W.; Ohama, Y.; Demura, K. Drying Shrinkage Reduction of Polymer-Modified Mortars Using Redispersible Polymer Powder by Use of Shrinkage-Reducing Agents. J. Soc. Mater. Sci. Jap. 1997, 46, 84-88. [CrossRef]

(C) 2019 by the author. Licensee MDPI, Basel, Switzerland. This article is an open access article distributed under the terms and conditions of the Creative Commons Attribution (CC BY) license (http://creativecommons.org/licenses/by/4.0/). 